\title{
Oxidation and Characterization of Low-Concentration Gas in a High-Temperature Reactor
}

\author{
Jinhua Chen ${ }^{1,2, *}$, Guangcai Wen ${ }^{1,2}$, Song Yan ${ }^{3}$, Xiangyun Lan ${ }^{1,2}$ and Lu Xiao ${ }^{1,2}$ \\ 1 State Key Laboratary of the Gas Disster Detecting, Preventing and Emergency Contrlling, Chongqing 400037, \\ China;wgc139@126.com (G.W.); lanxiangyun@cqccteg.com (X.L.); xiaolu8317@126.com (L.X.) \\ 2 China Coal Technology Engineering Group Chongqing Research Institute, Chongqing 400037, China \\ 3 College of Mining and Safety Engineering, Shandong University of Science and Technology, Qingdao 266590, \\ China; yansongn1@163.com \\ * Correspondence: cqchenjinhua@126.com or 2005005@cqccteg.com
}

Received: 27 February 2020; Accepted: 13 April 2020; Published: 21 April 2020

check for updates

\begin{abstract}
To achieve the efficient utilization of low-concentration mine gas, reduce resource waste and alleviate environmental pollution, the high-temperature oxidation of low-concentration gas at a concentration range of $1.00 \%$ to $1.50 \%$, which is directly discharged into the atmosphere during coal mine production, was carried out to recover heat for reuse. The gas oxidation equipment was improved for the heating process and the safety of low-concentration gas oxidation under a high-temperature environment was evaluated. The experimental results showed that the reactor could provide a $1000{ }^{\circ} \mathrm{C}$ high-temperature oxidation environment for gas oxidation after installing high-temperature resistant ceramics. The pressure variation curves of the reactor with air and different concentrations of gas were similar. Due to the thermal expansion, the air pressure slightly increased and then returned to normal pressure. In contrast, the low-concentration gas exhibited a stable pressure response in the high-temperature environment of $1000^{\circ} \mathrm{C}$. The outlet pressure was significantly greater than the inlet pressure, and the pressure difference between the inlet and outlet exhibited a trend to increase with the gas concentration. The minimum pressure difference was $4 \mathrm{kPa}$ (air) and the maximum was $11 \mathrm{kPa}(1.50 \%$ gas). The explosion limit varied with the temperature and the blend of oxidation products. The ratio of measured gas pressure to air pressure after oxidation was below the explosion criterion, indicating that the measured concentration of gas is still safe after the shift of the explosion limit, which provides a safe concentration range for the efficient use of low-concentration gas in the future.
\end{abstract}

Keywords: low-concentration; gas; reactor; high-temperature oxidation

\section{Introduction}

Coal mines emit a large amount of low-concentration gas every year. However, unstable gas source conditions and low long-term utilization rates lead to a waste of energy and high greenhouse gas emissions [1]. Therefore, low-concentration gas utilization is an important issue that needs to be resolved currently.

Low-concentration gas emits heat at high-temperatures, which not only provides energy for gas oxidation but also affords the remaining heat for utilization [2]. The residual heat after gas oxidation from a gas concentration of $0.4 \%$ or more has economic value [3] and the utilized concentration is generally controlled at $1.2 \%$ [4].

However, the intermediates of gas oxidation are complicated [5] and the mixed gas also affects the gas explosion limit [6]. Depending on its physical properties and chemical suppression performance [7], $\mathrm{CO}_{2}$ has the function of suppressing the explosion. Specifically, the upper and lower flammable limits 
of $\mathrm{CH}_{4}$ were both reduced by the introduction of $\mathrm{CO}_{2}$ [8]. The flammability limit of gas in mixtures with water vapor was narrower than in dry gas-air mixtures [9]. The final products of a gas reaction are generally water vapor and carbon dioxide, so the mixed products affect the limited movement of an explosion. The mitigating effect of ultra-fine water mist on the explosion of a hydrogen-gas mixture reduced the flame temperature, and the mitigation effect gradually increased with the increase in the fine water mist flux [10]. Water mist could alleviate low-concentration (6\%) gas explosions. Under high-concentration conditions of $9 \%, 11 \%$ or $13 \%$ [11], water mist still exhibited a significant suppressing effect on gas explosions [12]. The reaction temperature and pressure affect the explosion limit. With decreasing initial temperature, the maximum explosive pressure increased and the density of the flammable mixture increased [13]. The higher the initial pressure or temperature, the higher the upper flammable limit [14]. The flammable limit of the natural gas-air mixture at $20 \mathrm{MPa}$ and $100{ }^{\circ} \mathrm{C}$ increased significantly from $4.95 \%$ to $15.51 \%$ at room temperature $\left(0.1 \mathrm{MPa}\right.$ and $\left.25^{\circ} \mathrm{C}\right)$ to $2.87-64.40 \%$. With the increase in pressure and temperature, the change in the upper flammable limit (UFL) was more sensitive than the change in the lower flammable limit (LFL) [15]. Within the temperature range of $25-100^{\circ} \mathrm{C}$, with the increase in the initial pressure, the UFL and LFL showed logarithmic growth and logarithmic decay, respectively, while the UFL and LFL increased linearly with the change in the initial temperature. The gas system was in an oxygen-depleted state near the upper flammable limit with the generation of $\mathrm{CO}$ during the production process. In contrast, the gas system was in an oxygen-rich state near the lower explosion limit, in which the reacted gases were almost all $\mathrm{CO}_{2}$ [15]. With the increase in the initial temperature, the peak explosion pressure decreased while the heat release rate accelerated. The addition of the diluent gas significantly reduced the explosion pressure [16]. The lower limit of the flammability of the gas at high pressure was slightly reduced. However, when the gas concentration was above $3 \mathrm{MPa}$, the upper limit of flammability was significantly increased. In the meantime, the theoretical limit of the oxygen concentration required for the explosion was gradually reduced, which increased the explosion hazard [17]. Researchers have conducted a lot of research on the reaction in the reactor, but they have not directly used the low-concentration gas effectively in the actual situation of a coal mine. When the temperature rises to $1000{ }^{\circ} \mathrm{C}$, a low concentration of gas still poses the risk of an explosion. Our research is based on the actual production activities of a coal mine, aiming to realize the efficient utilization of low-concentration gas discharged from a coal mine.

In this paper, $1.00-1.50 \%$ mine gas was used at a high temperature of $1000{ }^{\circ} \mathrm{C}$. The heating performance of the reactor, the oxidation pressure curve of the gas in the reactor and the gas inlet and outlet pressures were measured. The oxidation reaction of the gas was evaluated to characterize the gas explosion. This work provides a theoretical basis for the efficient use of low-concentration gas.

\section{Theory and Experiment}

\subsection{Gas Oxidation Equation}

The exothermicity of gas oxidation is complicated. The gas oxidation reaction generates various intermediates, but the final products are generally considered to be water and carbon dioxide [18] (Figure 1). In low-concentration gas heat storage and oxidation utilization technology, gas is heated to more than $700{ }^{\circ} \mathrm{C}$ by a high-temperature heat storage ceramic and heat is released by super enthalpy combustion. The chemical reaction equation is as follows (1):

$$
\mathrm{CH}_{4}+2 \mathrm{O}_{2}=\mathrm{CO}_{2}+2 \mathrm{H}_{2} \mathrm{O}+803 \mathrm{~kJ} / \mathrm{mol}
$$

It can be seen from the chemical reaction equation that the heat generating capacity of gas is directly proportional to its concentration. However, the concentration of the lower limit of a gas explosion decreases with the increase in temperature. 


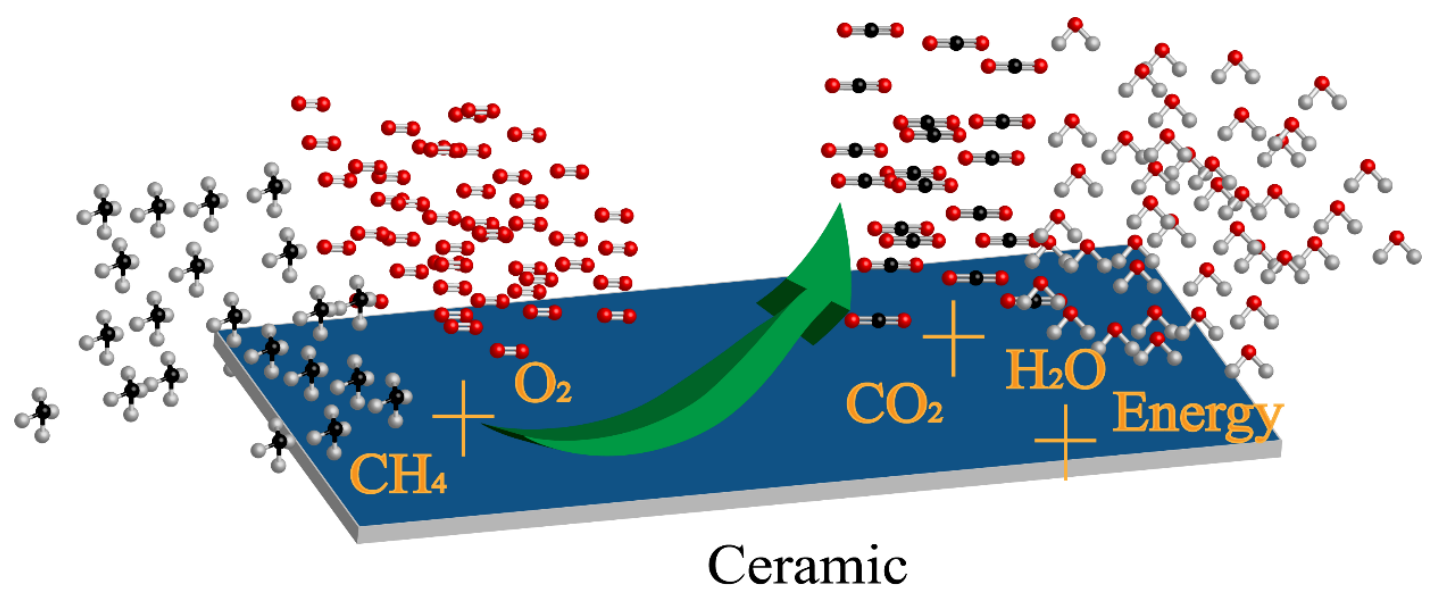

Figure 1. Exothermic oxidation of the gas.

\subsection{Equipment Optimization}

To improve the heating capacity of the equipment and ensure that the equipment can provide a stable high-temperature environment, high-temperature ceramics were installed in the reactor (Figure 2). The maximum temperature of this experiment was $1000^{\circ} \mathrm{C}$ and the preheating temperature of the heat storage body should be higher than this temperature. Therefore, a square of corundum mullite material was used (Table 1), which has a maximum service temperature of $1500{ }^{\circ} \mathrm{C}$.

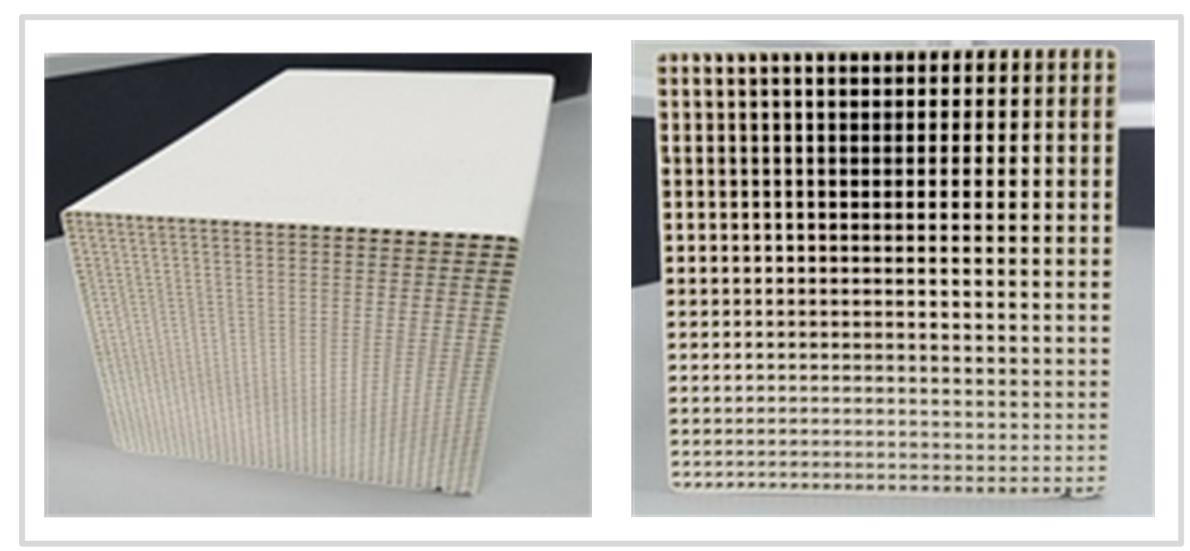

Figure 2. Reactor ceramics.

Table 1. Ceramic parameters.

\begin{tabular}{|c|c|c|c|c|}
\hline $\begin{array}{c}\text { Dimension } \\
\text { (Length, Width, } \\
\text { Height m) }\end{array}$ & $\begin{array}{l}\text { Single Pore Side } \\
\text { Length m }\end{array}$ & Number of Pores & $\begin{array}{c}\text { Pore Surface } \\
\text { Area } \mathrm{m}^{2}\end{array}$ & Mass kg \\
\hline $0.15 \times 0.15 \times 0.3$ & $\mathrm{e}=0.003$ & $40 \times 40$ & 5.8 & 5.71 \\
\hline Volume $\mathrm{m}^{3}$ & $\begin{array}{l}\text { Single Pore Side } \\
\text { Thickness m }\end{array}$ & Porosity & $\begin{array}{c}\text { Specific Surface } \\
\text { Area } \mathrm{m}^{2} / \mathrm{m}^{3}\end{array}$ & $\begin{array}{c}\text { Heating up to } \\
1000^{\circ} \mathrm{C} \text { Required } \\
\text { Energy kJ }\end{array}$ \\
\hline 0.00675 & $a=0.00075$ & $65 \%$ & 859 & 10352 \\
\hline
\end{tabular}

\subsection{Experimental Parameters}

The control parameters of this experiment were mainly temperature $(\mathrm{T})$, combustor cavity volume $(V)$, inlet pressure $(P)$, ventilation volume flow (qv), ventilation time $(\mathrm{t})$ and gas concentration $(\mathrm{n} \%)$. Specifically, the cavity volume of the combustor was $\mathrm{V}=35.6 \mathrm{~L}$. This experiment aimed to identify 
the relationship between the lower flammable limit and temperature, so the inlet pressure was taken as normal pressure; that is, $\mathrm{P}=\mathrm{P}_{0}=101.3 \mathrm{KPa}$. Since the inlet pressure was taken as a fixed value, the measured maximum airflow of the system was qv $=400 \mathrm{~L} / \mathrm{min}$. Subsequently, the airflow time was obtained as below:

$$
\mathrm{t}=\frac{V}{q_{v}}=\frac{35.6 \mathrm{~L}}{400 \mathrm{~L} / \min }=5.34 \mathrm{~s}
$$

\subsection{Explosion Criterion}

The gas storage oxidation reaction was carried out at a high temperature of more than $700{ }^{\circ} \mathrm{C}$. The increase in temperature reduces the lower limit concentration of gas explosion. Therefore, under the influence of multiple factors, the high-temperature oxidation of low-concentration gas at $1000{ }^{\circ} \mathrm{C}$ will also explode. To achieve the safe and efficient utilization of low-concentration gas, this experiment focused on the oxidation test for $1.00-1.50 \%$ concentration gas. The explosion criterion (P2/P1 $\geq 1.07)$ of this test was the ratio of the pressure of the gas to the pressure of air after the temperature rising, which was used to characterize the reaction in the reactor $[19,20]$.

\subsection{Experimental Process}

The reaction equipment was mainly composed of three systems: the inlet/exhaust system, the combustor and the monitoring system (Figure 3). The gas oxidation was mainly completed in the combustor.

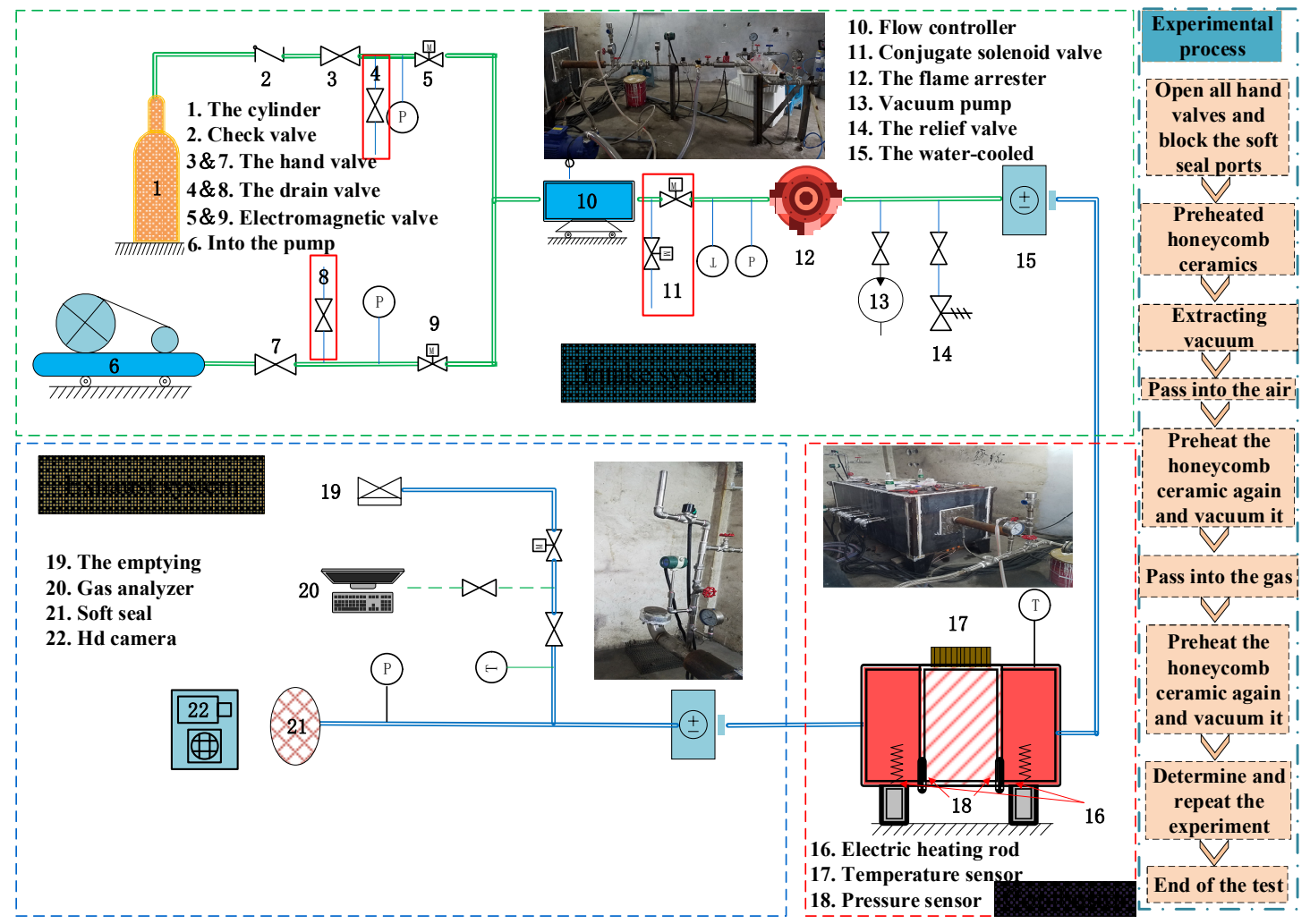

Figure 3. Experimental equipment and process.

\section{Results and Discussion}

\subsection{Discussion of Heating Capacity of Improved Equipment}

At the target temperature range of $800-1050{ }^{\circ} \mathrm{C}$, the experimental results of the combustor temperature rising are shown in Figures 4 and 5. 


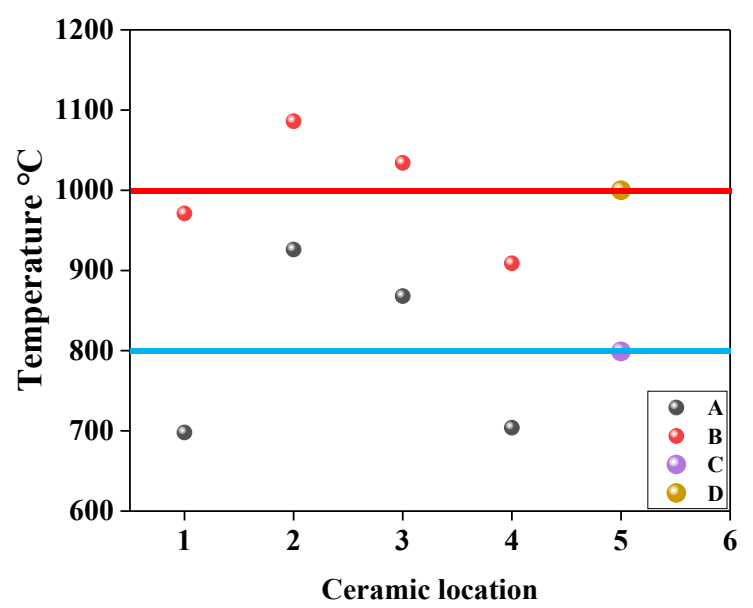

Figure 4. Empty chamber temperature.

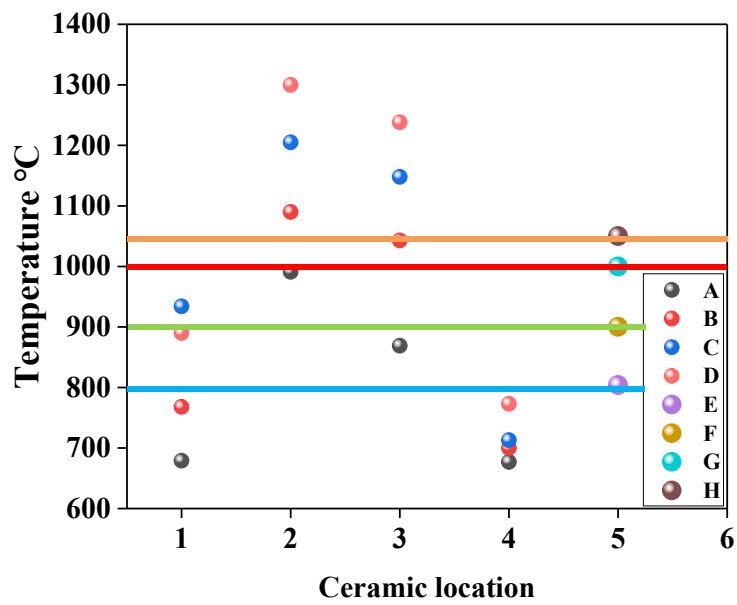

Figure 5. Temperature after installing the ceramic.

Figure 4 is a test of the heating capacity of the reactor when the reactor is empty: 1, 2, 3 and 4 are the sensor placement positions, and 5 is the overall temperature of the reactor. A and B are the preset test points for $800{ }^{\circ} \mathrm{C}$ and $1000{ }^{\circ} \mathrm{C}$, respectively. $\mathrm{C}$ and $\mathrm{D}$ are the overall temperature of the reactor at the preset temperature. From the actual test data, it is known that, due to the difference in the position of the sensors placed inside the reactor and the non-uniformity of the rise in temperature in the same time in different positions of the reactor, the gap between different sensors is large. When the preset temperature was $800^{\circ} \mathrm{C}(\mathrm{A})$, the rise in temperature at different locations in the same time was different, but the temperature reached by the gas oxidation reaction in the reactor at $23 \mathrm{~h}$ was $799^{\circ} \mathrm{C}$, which is $1{ }^{\circ} \mathrm{C}$ different from the preset temperature. The difference between the actual temperature and the preset temperature was small, so the reactor can provide a high-temperature reaction environment when the preset temperature is $800^{\circ} \mathrm{C}$. When the preset concentration was $1000^{\circ} \mathrm{C}(\mathrm{B})$, the temperature varied at different locations. After heating for $28 \mathrm{~h}$, the temperature in the reactor chamber reached $1000{ }^{\circ} \mathrm{C}$, which indicates that the reactor has the ability to provide a high-temperature oxidation environment for gas reactions in the case of an empty chamber.

Figure 5 is a test of the heating capability after the high-temperature ceramic is installed. Note that $1,2,3$ and 4 are the positions of sensors placed near the ceramic, respectively, and 5 is the overall temperature in the reactor after the ceramic is heated. A, B, C and D are test points for heating up at preset temperatures of $800{ }^{\circ} \mathrm{C}, 900{ }^{\circ} \mathrm{C}, 1000{ }^{\circ} \mathrm{C}$ and $1050{ }^{\circ} \mathrm{C}$, respectively. E, F, G and $\mathrm{H}$ are the overall temperature in the reactor at preset temperatures of $800^{\circ} \mathrm{C}, 900{ }^{\circ} \mathrm{C}, 1000{ }^{\circ} \mathrm{C}$ and $1050{ }^{\circ} \mathrm{C}$, respectively. As can be seen from the figure, after the ceramic is placed, because the ceramic needs to be heated, there will also be slight differences between the different ceramics and the heating 
condition is more complicated than when the cavity is empty. When the preset temperature was $800{ }^{\circ} \mathrm{C}$ (A), the temperature varied at different locations, but the temperature reached by the gas oxidation reaction in the reactor at $23 \mathrm{~h}$ was $800{ }^{\circ} \mathrm{C}$, which is the same as the preset temperature, so when the temperature is $800{ }^{\circ} \mathrm{C}$, the reactor can provide a high-temperature reaction environment. When the preset concentration was $900{ }^{\circ} \mathrm{C}(\mathrm{B})$, the temperature varied at different positions. After heating for $23 \mathrm{~h}$, the temperature in the reactor chamber reached $899^{\circ} \mathrm{C}$, which was $1{ }^{\circ} \mathrm{C}$ different from the preset temperature, and the difference was small, indicating that the reactor had the ability to provide a high-temperature oxidation environment for gas reactions. When the preset temperature was $1000{ }^{\circ} \mathrm{C}$ (C), the rise in temperature at different locations in the same time was different, but the temperature reached by the gas oxidation reaction in the reactor at $23 \mathrm{~h}$ was $1000^{\circ} \mathrm{C}$, which is the same as the preset temperature, so when the preset temperature is $1000^{\circ} \mathrm{C}$, the reactor can provide a high-temperature reaction environment. In order to prevent the reactor temperature from being too high to affect the performance and danger, we increased the preset temperature to $1050{ }^{\circ} \mathrm{C}$. After testing, although the temperature displayed by the sensors at different locations was different, the overall temperature was $1050{ }^{\circ} \mathrm{C}$, and when the temperature reached $1050{ }^{\circ} \mathrm{C}$, the reactor components and sensors were in good condition, indicating that the reactor had been improved to provide safety for low-concentration gas and the ability to oxidize the environment at high temperatures.

\subsection{Measured Pressure Chart of Gas Oxidation at $900^{\circ} \mathrm{C}$}

At the average ceramic temperature of $968.3^{\circ} \mathrm{C}$ and a vacuum of approximately $30 \mathrm{kPa}$, the air was quickly pumped in and the pressure of the gas oxidation was measured in real-time. The picture shows the real-time pressure detection chart.

Figure 6 is the actual measurement of flashover air pressure. It can be seen from the Figure that the initial measured flashover pressure fluctuated steadily around $99.75 \mathrm{kPa}$, but the pressure increased significantly around $166.33 \mathrm{~s}$ and fluctuated steadily again around $101.25 \mathrm{kPa}$ after the pressure spike. Since the ceramic is affected by the airflow during the evacuation, the temperature will be significantly reduced and recovered in a short time. After flashing air, the pressure in the chamber increased with the temperature recovery and air expansion after heating. A spiking value was detected in the pressure. The pressure after the air flashing was $101.4 \mathrm{kPa}$.

The airflow was set to $400 \mathrm{~L} / \mathrm{min}$, and the airflow time was set to $5.3 \mathrm{~s}$. After several tests, the inlet pressure was set to $400 \mathrm{kPa}$. Figure 7 shows the measured pressure at the ceramic temperature of $900{ }^{\circ} \mathrm{C}$.

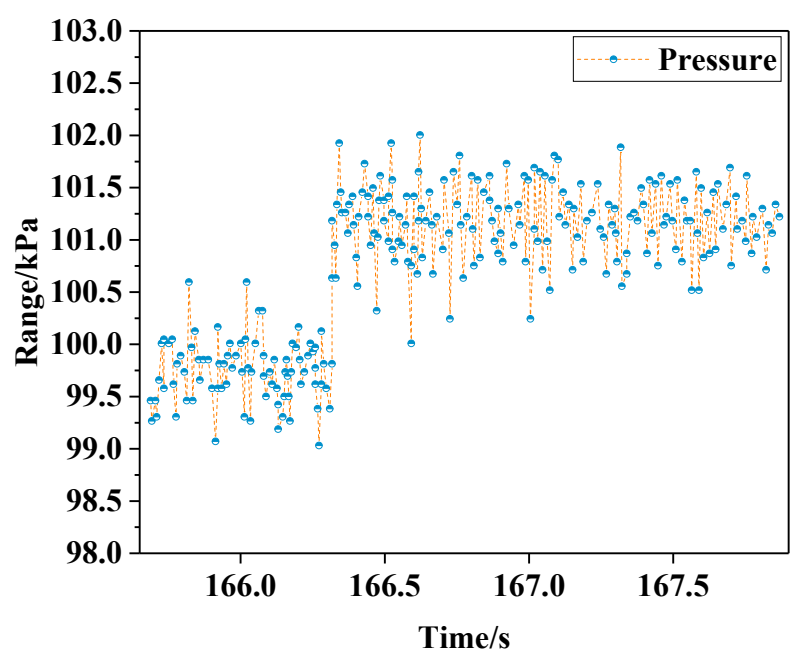

Figure 6. Measured flashover air pressure. 


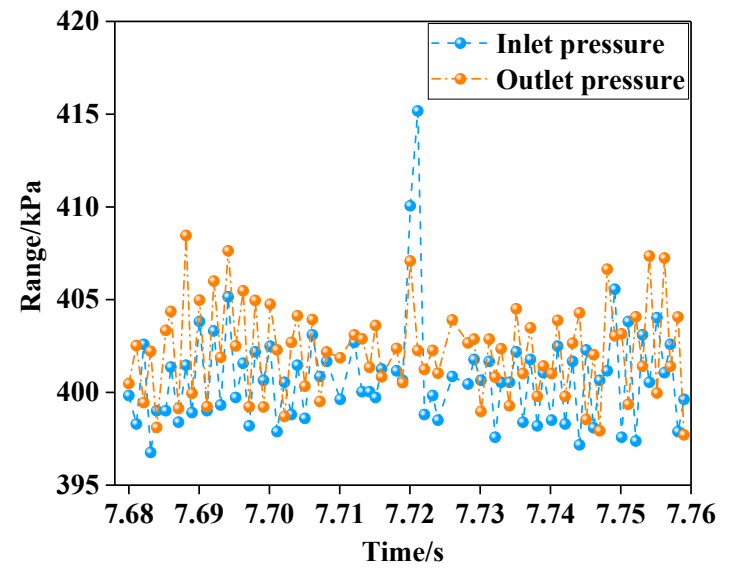

(a)

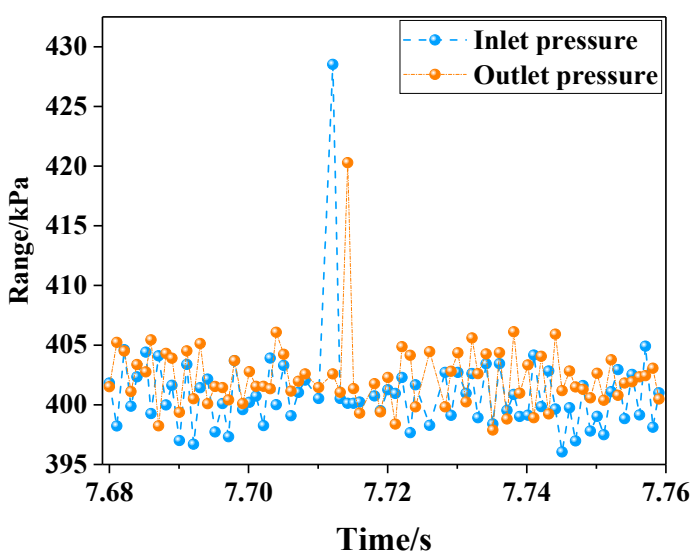

(c)

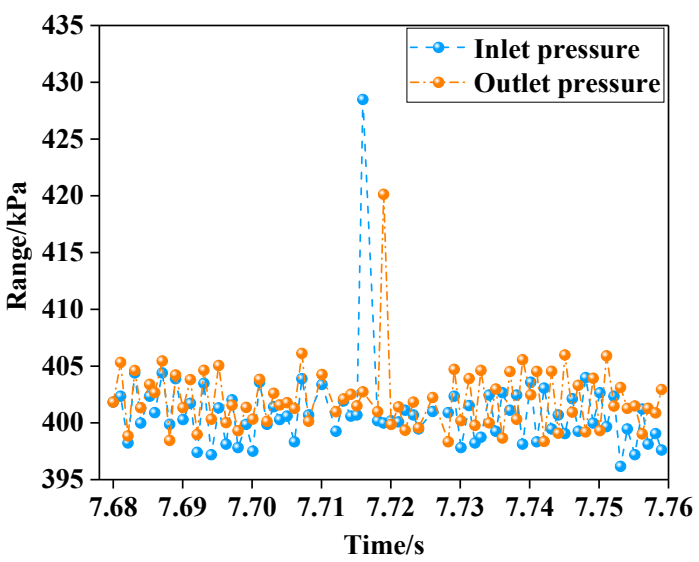

(e)

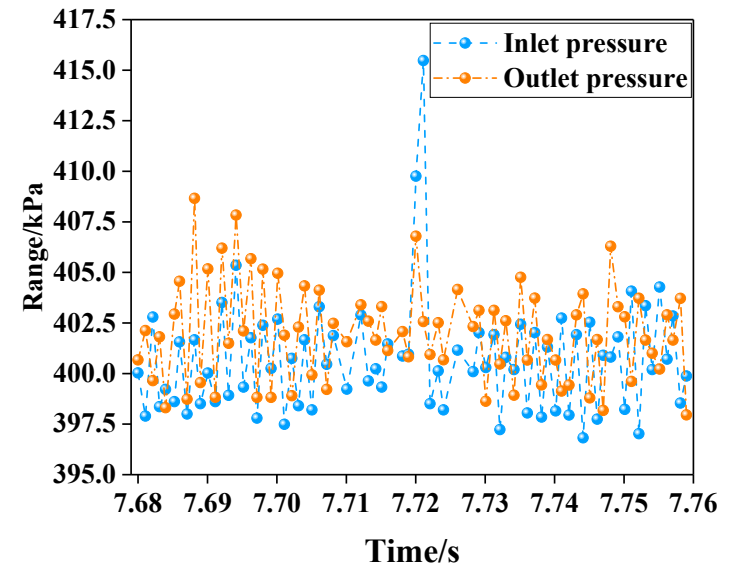

(b)

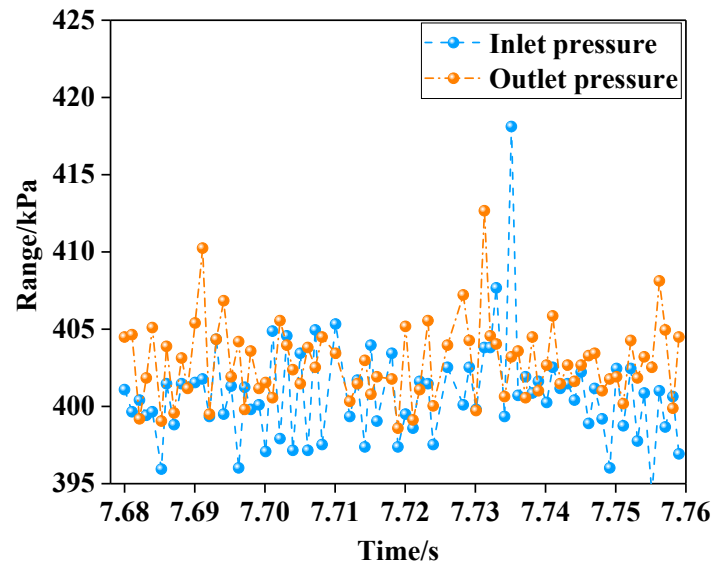

(d)

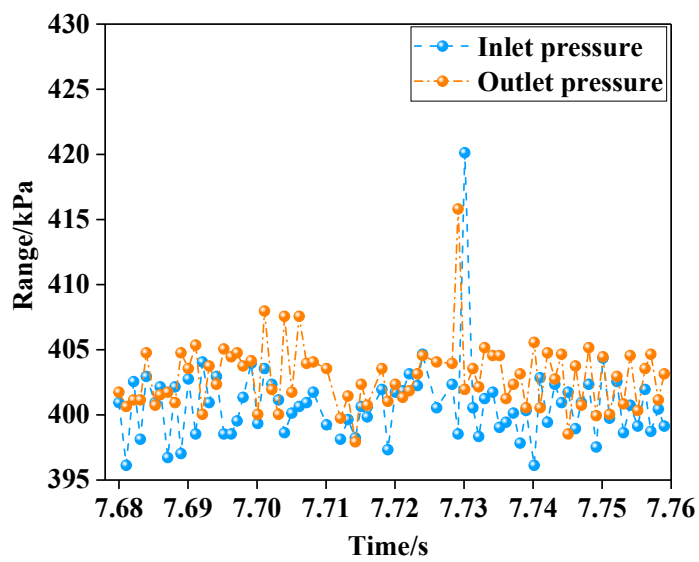

(f)

Figure 7. Cont. 


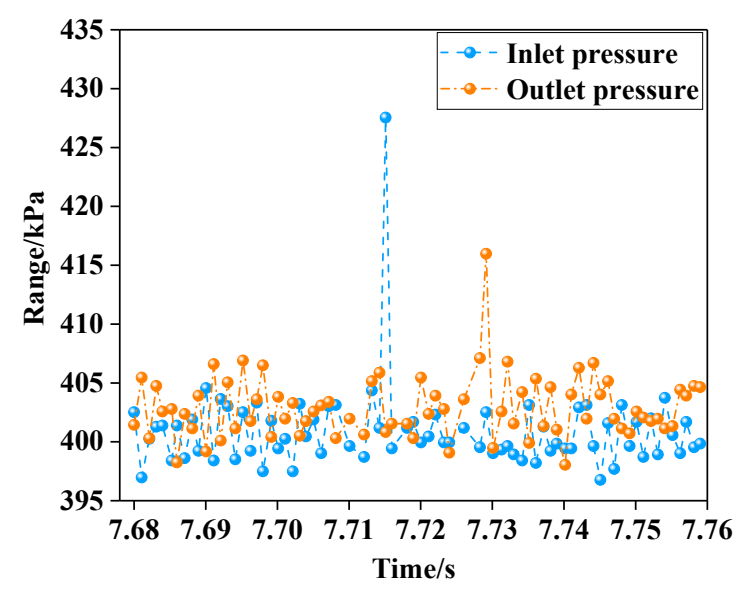

$(\mathrm{g})$

Figure 7. Experimental pressure detection chart (a, b, c, d, e, f and $\mathbf{g}$ show the pressures of air (a) and gas concentrations of $1.00 \%, 1.10 \%, 1.20 \%, 1.30 \%, 1.40 \%$ and $1.50 \%$ ).

Figure 7 is the experimental pressure chart. a-g show the pressures of air (a) and gas concentrations of $1.00 \%, 1.10 \%, 1.20 \%, 1.30 \%, 1.40 \%$ and $1.50 \%$, respectively, at the inlet pressure of $400 \mathrm{kPa}$ and the measured ceramic temperature of $900{ }^{\circ} \mathrm{C}$. Figure 7 is a data fragment from a large amount of data, mainly due to a jump in pressure detected near the fragment. We analyzed a small portion of the maximum jump value and showed the volatility in detail. It can be seen that when the inlet pressure was constant, the pressure change when passing air or gas was almost the same, without a detected difference. A peak appeared in the air pressure curve, which was ascribed to the rapid air expansion after the ceramic temperature recovered, but the expansion range was small and the inlet and outlet pressures returned to normal as the air concentration increased. The pressure change curves of different concentrations of gas were similar to a maximum peak. Their increase ranges were greater than those of air because gas enters a high-temperature environment and is oxidized to generate water and carbon dioxide, and releases heat. The volume of gas expands when absorbing heat. However, the generated carbon dioxide and water vapor are mixed with gas, which reacts with oxygen at high temperatures to continuously generate more intermediates. As the reaction proceeds, more carbon dioxide and water vapor are generated, which suppresses the increase in pressure and eventually the pressure becomes normal. The overall fluctuation range of the inlet and outlet pressures was small, indicating that the gas in the reactor did not have a sudden volume expansion and a sudden pressure increase caused by oxidation. When gas is exposed to a high temperature, it reacts with oxygen to generate carbon dioxide and water vapor. A small amount of carbon dioxide and water vapor are mixed with the gas and continue to react with the gas, affecting the gas explosion limit. It can be seen from the figure that, compared with air, the gas mixed with a small amount of carbon dioxide and water vapor has a relatively stable reaction process, with no significant increase in pressure, indicating that the explosion limit of low-concentration gas changes slightly after mixing with a small amount of impurity gas. There was no instantaneous explosion in the instantaneous jump of pressure.

Figure 8 shows the gas flow pressure in and out of the equipment, which was obtained by averaging the overall data for each gas concentration corresponding to the inlet and outlet pressure. It can be seen that the gas pressures of different gases increased to varying degrees after passing through the heater. This phenomenon was attributed to the thermal expansion of the gas when passing through a high-temperature environment. When passing through a high-temperature environment, gas undergoes an oxidation reaction, releasing water vapor and carbon dioxide, which increases the gas pressure in a short time. The pressure of different types of gas is different, which results in different pressure at the outlet. However, the discrepancy between the two curves is small, indicating that the 
volume of the original gas does not increase sharply after passing through the ceramic heater and that the possibility of instant explosion is very slight.

Figure 9 shows the pressure difference between the inlet and the outlet. It can be seen that the air pressure difference was the smallest, indicating that the air has a smaller expansion volume when heated and has a lower risk of explosion. The maximum pressure difference of gas at a concentration of $1.5 \%$ indicates that the methane gas was instantaneously heated when passing through a high-temperature heat source. The gas expansion is caused not only by the expansion of its volume but also by the gas reaction that generates water vapor, carbon dioxide and heat. The volume of gas was significantly increased, with a maximum pressure difference of $11 \mathrm{kPa}$ when exiting the reactor. The pressure difference of gas was greater than the pressure difference of air when passing through the high-temperature heat source. The pressure difference of gas exhibited an increasing trend with the increase in the concentration, which indicates that the increase in the concentration enables the gas to tend to approach the pressure spike when passing through the high-temperature environment of $1000{ }^{\circ} \mathrm{C}$. The difference in the pressure difference between $1.4 \%$ and $1.5 \%$ gas after thermal oxidation was greater than that when the gas concentration increased by $0.1 \%$, indicating that the pressure difference changed more drastically when the gas concentration exceeded $1.4 \%$. During the gas concentration's increase from $1 \%$ to $1.5 \%$, the pressure difference did not change much, indicating that the pressure did not spike instantaneously.

Figure 10 shows the ratio of gas outlet pressure to air outlet pressure at different concentrations. $\mathrm{A}, \mathrm{B}, \mathrm{C}, \mathrm{D}, \mathrm{E}$ and $\mathrm{F}$ represent the ratios of gas outlet pressure to air outlet pressure at concentrations of $1.00 \%, 1.10 \%, 1.20 \%, 1.30 \%, 1.40 \%$ and $1.50 \%$, respectively. It can be seen that the ratio of the gas outlet pressure to the air outlet pressure was very different at different concentrations. The minimum value was observed at point $\mathrm{E}$, indicating that the measured gas concentration is the safest at $1.40 \%$ and the possibility of gas explosion is the minimum. The same maximum value was observed at points $D$ and $\mathrm{F}$, which indicates that a gas explosion is most likely and the most dangerous when the measured gas concentrations are $1.30 \%$ and $1.40 \%$. However, the measured data points are far less than 1.07, indicating that there is no danger of explosion in the measured concentrations of gas. This result demonstrates that there is no explosion risk in the gas concentration range of $1-1.5 \%$, in which the gas in the reactor is oxidized rather than exploding. The gas is fully oxidized without risk of explosion, which affords a high-temperature heat source. When using low-concentration gas from mines in the future, we can control the gas concentration to below 1.5\% with mixed air to achieve the safe and efficient utilization of low-concentration gas.

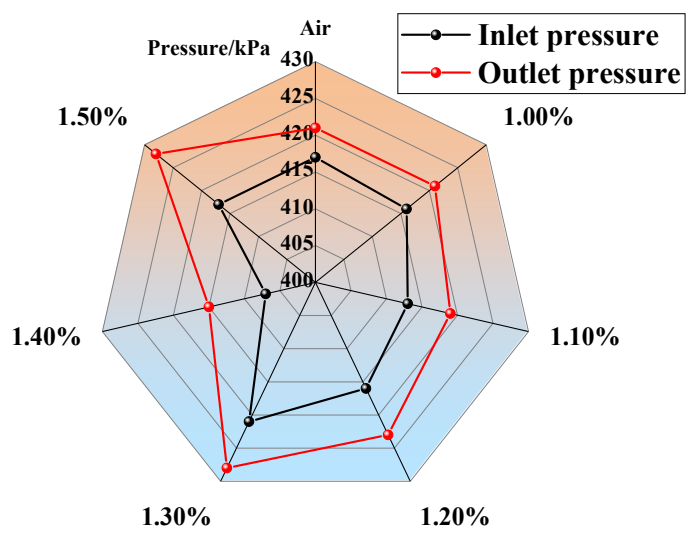

Figure 8. Inlet and outlet pressure. 


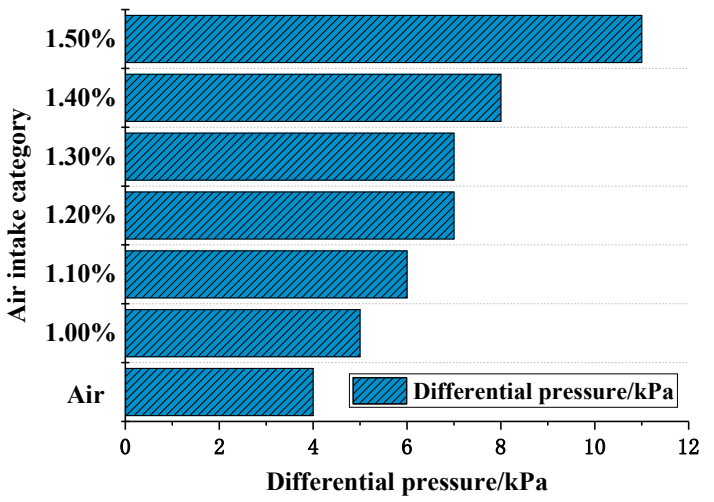

Figure 9. Pressure difference between inlet and outlet.



Figure 10. Explosion criteria.

\section{Conclusions}

To accomplish the use of low-concentration gas in coal mines, a self-developed oxidation reactor was used for the high-temperature oxidation of the gas. The gas reaction was characterized by the pressure difference between the inlet and outlet. The conclusions of the study are as follows.

1. The reactor has the ability to provide a high-temperature reaction environment at $1000{ }^{\circ} \mathrm{C}$ for low-concentration gas oxidation.

2. The pressure variation curves of the reactor with air and different concentrations of gas were similar. The gas in the reactor did not exhibit a sudden volume expansion or a sudden pressure increase due to oxidation. Compared with air, the pressure of gas mixed with a small amount of carbon dioxide and water vapor did not fluctuate significantly during the further reaction.

3. The inlet and outlet pressures of $1.00-1.50 \%$ concentration gas were at similar levels. Their pressure difference was slight, indicating that there was no instant increase in pressure in the gas reactor. The minimum pressure difference was $4 \mathrm{kPa}$ (air) and the maximum was $11 \mathrm{kPa}(1.50 \%$ gas). The ratio of low-concentration gas outlet pressure to air outlet pressure was less than 1.07, indicating that no gas explosion occurred in the measured range. The safe oxidation gas concentration in the reactor was from $1.00 \%$ to $1.50 \%$ and the gas concentration of $1.40 \%$ had the minimum explosion probability, which provides the optimal concentration for future low-concentration gas oxidation utilization. This provides a premise for the utilization of waste heat in low-concentration gas (Figure 11). 


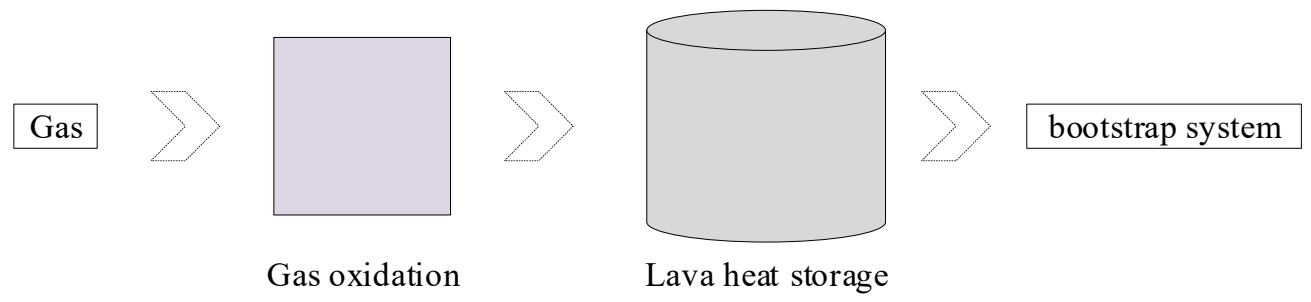

Figure 11. Low-concentration gas utilization system.

Author Contributions: Conceptualization, S.Y. and J.C.; methodology, G.W.; formal analysis, X.L.; investigation, L.X.; resources, J.C.; data curation, X.L.; writing—original draft preparation, S.Y.; writing—review and editing, S.Y.; supervision, J.C.; project administration, J.C.; funding acquisition, J.C. All authors have read and agreed to the published version of the manuscript.

Funding: This research was funded by the "Thirteenth Five-Year" National Science and Technology Major Funding Project (Project No. 2016ZX05045-006-002), Key projects supported by science and technology innovation and entrepreneurship fund of Tian Di Science \& Technology Co., Ltd (Project No. 2019-TD-ZD004), and Key projects supported by China Coal Technology Engineering Group Chongqing Research Institute (Project No. 2018ZDXM06).

Conflicts of Interest: The authors declared that they have no conflicts of interest to this work.

\section{References}

1. Marín, P.; Vega, A.; Díez, F.V.; Ordóñez, S. Control of regenerative catalytic oxidizers used in coal mine ventilation air methane exploitation. Process Saf. Environ. Prot. 2020, 134, 333-342. [CrossRef]

2. Gao, P. Application of low concentration coal mine methane (CMM) oxidization technology in coal refrigeration system. China Energy Environ. Prot. 2017, 39, 108-112.

3. Li, Q.; Lin, B.; Yuan, D.; Chen, G. Demonstrationand its validation for ventilation air methane (VAM) thermal oxi-dation and energy recovery project. Appl. Therm. Eng. 2015, 90, 75-85. [CrossRef]

4. $\mathrm{Li}, \mathrm{Z}$. Research status and application prospect of low concentration CBM utilization technology. Energy Environ. Prot. 2018, 40, 152-156.

5. He, Z.; Li, X.-B.; Liu, L.-M.; Zhu, W. The intrinsic mechanism of methane oxidation under explosion condition: A combined ReaxFF and DFT study. Fuel 2014, 124, 85-90. [CrossRef]

6. Stracher, G.B. Gases Generated During the Low-Temperature Oxidation and Pyrolysis of Coal and the Effects on Methane-Air Flammable Limits. In Coal and Peat Fires: A Global Perspective: Volume 5: Case Studies-Advances in Field and Laboratory Research; Elsevier: Amsterdam, The Netherlands, 2019; Volume 5, pp. 157-171.

7. Li, M.; Xu, J.; Wang, C.; Wang, B. Thermal and kinetics mechanism of explosion mitigation of methane-air mixture by N2/CO2 in a closed compartment. Fuel 2019, 255, 115747. [CrossRef]

8. Deng, J.; Cheng, F.; Song, Y.; Luo, Z.; Zhang, Y. Experimental and simulation studies on the influence of carbon monoxide on explosion characteristics of methane. J. Loss Prev. Process Ind. 2015, 36, 45-53. [CrossRef]

9. Shen, X.; Zhang, B.; Zhang, X.; Wu, S. Explosion behaviors of mixtures of methane and air with saturated water vapor. Fuel 2016, 177, 15-18. [CrossRef]

10. Wen, X.; Wang, M.; Su, T.; Zhang, S.; Pan, R.; Ji, W. Suppression effects of ultrafine water mist on hydrogen/methane mixture explosion in an obstructed chamber. Int. J. Hydrog. Energy 2019, 44, 32332-32342. [CrossRef]

11. Hoffman, R.E.; Darmon, E.; Aserin, A.; Garti, N. High accuracy NMR chemical shift corrected for bulk magnetization as a tool for structural elucidation of dilutable microemulsions. Part 1-Proof of concept. J. Colloid Interface Sci. 2016, 463, 349-357. [CrossRef] [PubMed]

12. Cao, X.; Ren, J.; Bi, M.; Zhou, Y.; Li, Y. Experimental research on the characteristics of methane/air explosion affected by ultrafine water mist. J. Hazard. Mater. 2017, 324, 489-497. [CrossRef] [PubMed]

13. Cui, G.; Wang, S.; Liu, J.; Bi, Z.; Li, Z. Explosion characteristics of a methane/air mixture at low initial temperatures. Fuel 2018, 234, 886-893. [CrossRef]

14. Li, P.; Liu, Z.; Li, M.; Huang, P.; Zhao, Y.; Li, X.; Jiang, S. Experimental study on the flammability limits of natural gas/air mixtures at elevated pressures and temperatures. Fuel 2019, 256, 115950. [CrossRef]

15. Huang, L.; Pei, S.; Wang, Y.; Zhang, L.; Ren, S.; Zhang, Z.; Xiao, Y. Assessment of flammability and explosion risks of natural gas-air mixtures at high pressure and high temperature. Fuel 2019, 247, 47-56. [CrossRef] 
16. Tang, C.; Zhang, S.; Si, Z.; Huang, Z.; Zhang, K.; Jin, Z. High methane natural gas/air explosion characteristics in confined vessel. J. Hazard. Mater. 2014, 278, 520-528. [CrossRef] [PubMed]

17. Niu, Y.; Shi, B.; Jiang, B. Experimental study of overpressure evolution laws and flame propagation characteristics after methane explosion in transversal pipe networks. Appl. Therm. Eng. 2019, 154, 18-23. [CrossRef]

18. Slepterev, A.A.; Salnikov, V.S.; Tsyrulnikov, P.G.; Noskov, A.S.; Tomilov, V.N.; Chumakova, N.A.; Zagoruiko, A.N. Homogeneous high-temperature oxidation of methane. React. Kinet. Catal. Lett. 2007, 91, 273-282. [CrossRef]

19. Gao, P.; Sun, D.; Huo, C.; Kang, J.; Zhao, X.; Chen, J.; Lan, B. Study progress on thermal oxidized utilization technology of ultralow concentration gas. Coal Sci. Technol. 2018, 12, 67-73. [CrossRef]

20. Kang, J.; Lan, B.; Yan, Z.; Gao, P.; Xu, H. Study on Regenerative Oxidation Test of Ventilation Air Methane. Min. Saf. Environ. Prot. 2013, 14, 75-88.

(C) 2020 by the authors. Licensee MDPI, Basel, Switzerland. This article is an open access article distributed under the terms and conditions of the Creative Commons Attribution (CC BY) license (http://creativecommons.org/licenses/by/4.0/). 